\title{
Geographical patterns in seasonal changes of body mass, skull and brain size of common shrews
}

\author{
Javier Lázaro ${ }^{1}$, Lucie Nováková ${ }^{2},{\text { Moritz } \text { Hertel }^{3} \text {, Jan Taylor }}^{4}$, Marion Muturi ${ }^{1}$, Karol \\ $\mathrm{Zub}^{5}$, and Dina Dechmann ${ }^{1}$ \\ ${ }^{1}$ Max Planck Institute of Animal Behavior \\ ${ }^{2}$ Charles University Faculty of Science \\ ${ }^{3}$ Max-Planck-Institute for Ornithology \\ ${ }^{4}$ University of Bialystok \\ ${ }^{5}$ Polish Academy of Sciences Mammal Research Institute
}

June 8, 2020

\begin{abstract}
1. Some small mammals exhibit Dehnel's phenomenon, a drastic decline in body mass, braincase and brain size from summer to winter, followed by a regrowth in spring. This is accompanied by a reorganization of the brain and changes in other organs. The evolutionary link between these changes and seasonality remains unclear, although the magnitude of change varies between locations as the phenomenon is thought to lead to energy savings during winter. 2. Here we explored geographic variation of the intensity of Dehnel's phenomenon in Sorex araneus. We compiled the literature on seasonal changes in braincase size, brain and body mass, supplemented by our own data from Poland, Germany and Czech Republic. 3. We analysed the effect of geographic and climate variables on the magnitude of change and patterns of brain reorganization. 4 . From summer to winter the braincase height decreased by $13 \%$, followed by $10 \%$ regrowth in spring. For body mass the changes were $-21 \% /+82 \%$, respectively. Changes increased along the north-east axis. Several climate variables were correlated with these transformations, confirming a link of the magnitude of the changes with environmental conditions. This relationship differed for the brain mass decline vs. regrowth, suggesting that they may have evolved under different selective pressures. 5. We found no geographic trends explaining variability in the brain mass changes although they were similar $(-21 \% /+10 \%)$ to those of the braincase size. Underlying patterns of change in brain organisation in North-Eastern Poland were almost identical to the pattern observed in Southern Germany. This indicates that local habitat characteristics may play a more important role in determining brain structure than broad scale geographic conditions. 6. We discuss the techniques and criteria used for studying this phenomenon, as well as its potential presence in other taxa and the importance of distinguishing it from other kinds of seasonal variation.
\end{abstract}

\section{INTRODUCTION}

The adaptive value of phenotypic traits can be identified only when functional correlations with environmental variables are considered. The variation of the phenotypes between populations and individuals is often used to address this. However, individual phenotypic flexibility, where the adult phenotype can still be modified in response to environmental change, can be hidden by this approach (Piersma \& Drent, 2003). A special case of such phenotypic change is life-stage cycling, i.e. seasonal changes along the lifetime of individuals that are reversible. Studying life-stage cycling allows inferring mechanisms of adaptation to the environment as the changes are well marked and predictable.

An outstanding case of seasonal phenotypic flexibility are the drastic but reversible morphological changes called Dehnel's Phenomenon, observed in some small, short-lived mammals with high metabolic rates. In this phenomenon young animals reach a first maximum size in their first summer, followed by a size decline 
reaching a minimum size in winter, They then regrow in the spring along with sexual maturation. Best studied in the common shrew (Sorex araneus), Dehnel's Phenomenon entails a decrease in overall size, the size of the skull and other parts of the skeleton, but also the brain and many other organs and tissues, followed by regrowth (Dehnel, 1949; Pucek, 1965). Brain mass, for example, decreases by up to $30 \%$ from summer to winter and increases again by 10-17\% during the next spring and summer (Bielak \& Pucek, 1960; Lázaro et al. , 2018a). Braincase height, often used as a proxy for braincase size, decreases by up to $18 \%$ and regrows by up to $15 \%$ (Crowcroft \& Ingles, 1959; Homolka, 1980; Yaskin, 1994). Importantly, Dehnel's Phenomenon causes not just a rescaling of the animal, but each organ and even each brain region shows a unique pattern of the direction and magnitude of changes, resulting in several completely different phenotypes along the year (Yaskin, 1994; Lázaroet al. , 2018b). Also the length of the spine decreases and regrows seasonally as a result of shrinkage of the inter-vertebral disks (Saure \& Hyvärinen, 1965; Hyvarinen, 1969). Some other species of shrews, and, as has recently been found, some mustelids, also show seasonal reversible shrinkage and regrowth at least of their skulls and brains (Dechmann et al. , 2017; LaPoint et al. , 2017).

Species known to exhibit Dehnel's Phenomenon are small short-lived predators with very high metabolic rates, which do not hibernate or migrate during winter (Taylor, 1998; Ochocińska \& Taylor, 2005). They remain active and dependent on high quality food year-round and the reversible changes of body and brain are hypothesized to be a winter adaptation to save energy (Mezhzherin, 1964; Pucek, 1970; Yaskin, 2011). While direct evidence of a link between the changes in overall size or specific organs such as the brain and individual survival is still lacking, reducing metabolically expensive organs, including the brain during winter, is thought to decrease overall energetic needs and thus food intake (Churchfield, 1982; Schaeffer et al. , 2020). This would then compensate for the disadvantages of being small, such as an increasingly unfavorable volume to surface ratio in winter (Bergmann 1848; Yom-Tov \& Yom-Tov, 2005). In support of this, mass corrected energy consumption remains constant across seasons despite large differences in ambient temperature, which means overall energy use and thus food requirements of the size-decreased subadult winter shrews is lower than in the juvenile summer animals and especially in the adult individuals, whose mass doubles in the spring (Gębczyński, 1965; Taylor, Rychlik, \& Churchfield, 2013; Schaeffer et al. , 2020). In addition, although this seasonal cycle occurs in every free-ranging individual (Lázaro et al. , 2017), the intensity of the size changes is exceptionally flexible. Captive shrews differ in the magnitude of seasonal change of skull size when ambient temperature is manipulated (Lázaro et al. , 2019).

Ambient conditions thus play an important role for Dehnel's Phenomenon, but whether as triggers or evolutionary drivers or both, remains unclear. Braincase changes associated with Dehnel's Phenomenon in weasels (Mustela erminea and M. nivalis ) vary greatly in intensity and timing between populations at different geographic locations (LaPoint et al. , 2017). Previous studies on common shrews suggested a greater winter decrease in skull and body size in Northeastern Europe compared to Southwestern populations (Pucek, 1970; Spitzenberger, 2001). Similarly, the reorganization of brain structure differs greatly between two populations in Radolfzell (Southern Germany, Lázaro et al. 2018b) and Russia (Yaskin, 1994). This increase in the extent of seasonal size change from regions with milder winter conditions to regions with harsher winter conditions supports the hypothesis that Dehnel's Phenomenon is a winter adaptation. In fact, this trend towards lower body size when facing harsh conditions also fits well to the contradictive morpho-geographical patterns observed inSorex shrews. Some Sorex species show lower body size at higher latitudes (Ochocińska \& Taylor, 2003), again contradicting Bergmann's rule that predicts larger bodies in colder climates to increase heat-preservation efficiency (Bergmann 1848, but see Zeveloff \& Boyce 1988). Several small mammal species follow a 'resource rule' where body size is directly predicted by resource availability (McNab, 2010). This would explain why common shrews decrease body size in winter, and predicts a more pronounced summer to winter shrinkage in environments with harsher winters - at high latitudes. However, a review of latitudinal differences in seasonal body mass decline did not find any significant trend (Ochocińska \& Taylor, 2003).

We compiled all published work on Dehnel's Phenomenon, discuss progress made since the last literature review in 1970 (Pucek, 1970) and take advantage of the larger currently available dataset to tatistically test for the influence of geographic and climatic variables on the magnitude of Dehnel's Phenomenon in 
S. araneus. We collected information from those studies which include changes in skull size and/or brain mass. From these studies, we also collected total body mass when reported and explored correlations of the intensity of Dehnel's Phenomenon with climatic and geographic variables. We added our own data on braincase size, brain mass and body mass from new populations in Poland and body mass and braincase size from the Czech Republic to this dataset. We expected to find increasing strength of Dehnel's Phenomenon along geographical gradient that fits increasingly harsh environmental conditions related to seasonality, as predicted by previous authors. In addition, we compiled information on Dehnel's Phenomenon in other species and compared their results with $S$. araneus. Finally, we specifically investigated the variation in the structural changes within the brain associated with Dehnel's Phenomenon between populations. We compared the divergent results from southern Germany (Lázaro et al. , 2018b) and Russia (Yaskin, 1994) with new data from a population in Northeastern Poland, situated geographically between these two. We expected to find intermediate values of structural change that would fit into a gradual, geographic pattern in this Polish population. The aim of this review is to establish an updated framework to study the evolutionary aspects of this fascinating phenomenon.

\section{METHODS}

\section{Data compilation on magnitude of size changes from literature}

We examined publications that report seasonal variation in skull size and/or brain mass in wild populations of the common shrew ( $S$. araneus ). From those publications, we additionally used values on total body mass when reported. For each study, we extracted the percentage of change from the first summer size peak to the winter minimum (decrease), and from winter to the second summer peak (regrowth) of each metric. Whenever estimations of the decrease and regrowth were not directly reported, we calculated them based on the published data. We determined the first size peak as the month with the highest mean value for juveniles; the winter minimum as the month with the lowest mean value for winter subadults; and the second size peak as the month with highest mean value for adults. Summer juveniles are immature young individuals born in late spring or summer; winter subadults are immature individuals, which are ca. six months old; adults are individuals in spring and summer which were born the previous year. As $S$. araneus has a maximum life span of 13-18 months, there is no overlap of sexually mature individuals from two generations. When sample size in a given month was low, we joined data from two or more consecutive months to determine the corresponding size extreme. The amount of change was calculated as the difference between mean values in the size extremes. We added to this data compilation from the literature our own data on the changes in braincase height, brain mass and/or body mass from four new populations (see below).

We determined coordinates and altitude for all locations as geographic variables. We extracted 19 bioclimatic variables from WorldClim Global Climate Data version 1.4 for all locations (Hijmans et al. , 2005) and used averaged values from data collected along 1960 - 1990 (see results section for details).

Following the criteria listed above, we also compiled the same information on seasonal morphological variation in other wild mammal species. However, the low number of publications prevented any statistical analysis.

\section{Skull dimension measurements from two museum collections}

We included detailed data on skull dimensions and body mass of $S$. araneus from two populations: Žofín, in the Novohradské hory mountain range (Czech Republic; 48.671838, 14.690402; new data) from the dry collection deposited at the Department of Zoology at the Charles University in Prague, which were collected from 1971 to 1977; and Białowieża National Park (Poland; 52.700000, 23.866667; Dechmann et al. 2017) at the Mammal Research Institute Polish Academy of Sciences. These specimens were collected in Białowieża National Park in 1946-1947, and also preserved dry. We used digital calipers $( \pm 0.01 \mathrm{~mm})$ to obtain braincase height, from the tympanic rings to the dorsal surface of the braincase, skull length, from the anteriormost projection of incisor 1 to the occipital condyle, maximum braincase width, and lower mandible length, from the alveolus dentalis of the incisor to the coronoid process. We focused our analyses on braincase height as we had previously found it to show the greatest change in response to Dehnel's Phenomenon (Lázaro et al. , 2017, 2018a). 


\section{Collection of own additional data from two free-ranging populations in Poland and Germany}

We added data we collected ourselves from two populations: Radolfzell, in the vicinity of Lake Constance (Germany; 47.764345, 8.997449; data published in Lázaro et al. (2018a); and Gugny, in the Biebrza National Park (Poland, 53.347487, 22.589436; new data). All handling and sampling methods in Poland were approved by the Ministry of Environment (DLP-III-4102-42/2607/14/MD, DLP-III.4102.136.2016.AK).

We captured shrews with wooden live traps (PPUH A. Marcinkiewicz, Rajgród, Poland) baited with mealworms and checked at 2-h intervals. In Radolfzell we trapped monthly from December 2013 to July 2016. In Gugny we trapped at the estimated peak periods of the morphological change cycle, in February, June and July 2014, May 2015 and May 2016. Immediately after capture, shrews were weighed $( \pm 0.01 \mathrm{~g})$ and carried to the laboratory where they were euthanized with anaesthesia overdose (Isoflurane) and perfused transcardially with phosphate-buffered saline (PBS) followed by $4 \%$ formaldehyde in PBS. Then we extracted the skull and used a digital caliper $( \pm 0.01 \mathrm{~mm})$ to obtain braincase height, skull length, and braincase width as described above for museum specimens. After this, we extracted the brain and weighed it $( \pm 0.001 \mathrm{~g})$. We size corrected brain mass by the maxillary tooth row length, which does not change seasonally and we obtained from post-mortem X-ray images of the skulls. This size-correction factor had been used for brain and brain regions volume in previous work (see Lázaro et al. (2017) for details).

We classified individuals as summer juvenile, winter subadult or adult based on the degree of gonadal development, capture date and degree of tooth wear (Pankakoski, 1989; Churchfield, 1990). For adults, sex can be directly determined visually. For immature individuals (juveniles and subadults) for which we could not directly check the gonads during dissection, we determined sex with a PCR-based gonosomal sexing method (Roos, DPZ Gottingen, unpublished). For this, we extracted DNA from tail tip samples with a standard DNeasy kit (Qiagen, GmbH, Hilden).

\section{Processing of brain tissue and calculation of brain region volumes}

We quantified the volumes of brain regions based on 3D reconstructions of serial-sectioned tissue as published in Lázaro et al. (2018b). Briefly, brains were cut sagittally in half and the two hemispheres were weighed to the nearest $0.001 \mathrm{~g}$. Then we fixated them for two weeks in PBS $4 \%$ paraformaldehyde and then transferred them to PBS $/ 0.1 \%$ sodium azide at $4{ }^{\circ} \mathrm{C}$ for long- term storage. We used the left hemispheres for all volume reconstructions. Before sectioning, we immersed the hemispheres in a series of PBS/10, 20 and $30 \%$ sucrose for cryoprotection. We cut the tissue in the coronal plane on a freezing sliding microtone (Reichert- Jung Hn-40) to obtain series of $30 \mu \mathrm{m}$-thick sections, of which we mounted every fifth section on microscope slides and stained them with $0.5 \%$ cresyl violet. We measured the following brain regions: olfactory bulb, neocortex, rhinal and piriform cortices, caudoputamen, amygdala, nucleus accumbens, thalamus, hypothalamus, hippocampus, dentate gyrus, CA1, CA2, CA3, subiculum and cerebellum and the total hemi-sphere (see Lázaro et al. (2018b) for details). To outline each region on the sections we use the software Neurolucida (MBF Bioscience, Williston, VT, USA) and we applied the Cavalieri principle to calculate the volume of each region based on the sum of the outlined areas multiplied by the section thickness and inter-section distance. This calculation was made automatically in Neurolucida Explorer. All data from Radolfzell were previously published in Lázaro et al. (2018b).

We accounted for shrinkage of tissue during the histological process with a correcting factor. This correcting factor was calculated for each brain as the quotient between the original hemisphere volume - determined by dividing the fresh hemisphere mass by the specific gravity of brain tissue (Stephan, 1960) - and the final volume of the hemisphere as determined by our reconstruction. The correction factor for each brain was then applied to the brain regions of that specimen. We also size corrected brain region volumes by the upper tooth row (which does not change in length over the year) obtained from X-ray images (Lázaro et al. , 2017).

\section{Data analyses}

Analyses of literature and own data

We analyzed the decrease and regrowth values of braincase height, brain mass, and body mass from all 
populations of $S$. araneus collected from the literature and the two new populations (Gugny and Žofín). To explore geographical trends in the decrease and/or regrowth of braincase height we fit two sets of four linear models using percentage of decrease (in the first set of models) or regrowth (in the second set) as response variable and a single dependent variable: longitude, latitude, altitude, or the interaction latitude X longitude. We fit the same sets of linear models for brain mass and body mass. Additionally, we used this same approach to analyze the geographical variation in overall size (braincase height, brain mass and body mass) in each of the age stages (juveniles, winter subadults and adults). Similarly, we fit linear models for these response variables with each of the climate variables.

\section{Detailed analyses of morphological trends in four populations}

To assess the differences in braincase height, skull length, braincase width, brain mass and body mass between stages of Dehnel's Phenomenon and locations, we used ANOVA for each of the five metrics. Dehnel's Phenomenon-stage was treated as a factor with three levels (summer juvenile, winter subadult, adult). We first assessed the effect of sex on our models, even though in our previous work we found no significant influence of sex on the seasonal changes of these variables (Lázaroet al. , 2017, 2018a). For each response variable (braincase height, skull length, braincase width, brain mass, and body mass) we compared two models using ANOVA: (M1) included season, location and sex and their interactions as explanatory variables. We removed sex from the second model (M2). We based our model selection on Akaike's information criterium (AIC) and chose M1 as final model for each metric only if it revealed a lower AIC value and the difference between the two models was significant. With the final model for each metric, we used Tukey tests to perform pair-wise comparisons between the factor levels.

Analyses of seasonal variation in size of brain regions in Poland and Germany

To analyze the variation in volume of brain regions between stages of Dehnel's Phenomenon, locations and sexes we used ANOVA for each brain region separately, with size corrected volume of the brain region as response variable and age, location and sex and their interactions as explanatory variables. Here, we included sex in the model based on the significant effect we had previously found on the seasonal changes of some brain regions in Radolfzell (Lázaro et al. , 2018b). To tease apart the influence of season, geographic difference, and sexual dimorphism, we did pair-wise comparisons between the factors' levels using Tukey tests for multiple comparisons.

All analyses were performed in R 3.5.0 (R Core Team, 2015).

\section{RESULTS AND DISCUSSION}

Large scale geographic differences in magnitude of seasonal changes of braincase height and body mass in $S$. araneus

Our results from the literature review confirmed large variation in the intensity of Dehnel's Phenomenon between populations. The data on decrease and regrowth of braincase height, brain mass and body mass in S. araneus are compiled in Table S1 (Supporting Information), and the list of corresponding references in the Supporting Information file. Mean \pm SD decrease in braincase height from first summer peak to winter minimum was $13.4 \pm 2.4 \%$ and regrowth from winter subadults to overwintered adults was $10.3 \pm$ $2.8 \%$. Proportion of braincase height decrease was positively correlated with latitude, longitude and their interaction (Fig. 1, Table 1) but not with altitude (Table 1). The large amount of variation in the intensity of Dehnel's Phenomenon between natural populations is consistent with the great flexibility of skull changes observed in the captive experiments when ambient temperature was manipulated (Lázaro et al. , 2019). Specifically, when analyzing braincase height variation across populations at each age stage, we found a negative correlation of braincase height with longitude and with the interaction of longitude and latitude at both the small subadult and regrown adult stages $(P$ (sub.-long.) $<0.05 ; P$ (sub.-long.:lat.) $<0.05 ; P$ (ad.-long.) $<0.05 ; P$ (ad.-long.:lat.) $<0.05$ ), but no trends along with other variables. This means that braincase height of subadults and adults, but not of juveniles, decreased towards the Northeast. We found a positive correlation in the magnitude of the decrease of braincase height with temperature seasonality, annual 
temperature range, and precipitation seasonality. We also found a negative correlation with isothermality and mean temperature of the driest quarter (Table 2). This suggests a link between braincase height decline and the intensity of seasonality, with a positive gradient towards more continental climate. This is also supported by the correlations we found between the intensity of Dehnel's Phenomenon and climate variables associated with seasonality. As it has been postulated that the size decrease stage of Dehnel's Phenomenon occurs in anticipation of changes in climate and resource variability (which is influenced by climate) this supports the hypothesis that shrews shrink in preparation of winter to lower their energetic needs and thus resource demands.

Even more interesting is then that we did not find a correlation between braincase height regrowth and any geographical variable (Table1). Braincase height regrowth was only positively correlated with precipitation during the warmest quarter (Table 2). It is striking that adult body mass as well as the size of several crucial organs greatly exceed subadult and even juvenile mass, while the size of the brain and skull are largest in juveniles and only partially regrow after the winter decrease (Pucek, 1965). Similarly, energy expenditure is by far the largest in these regrown adults (Schaeffer et al. , 2020) even they are exposed to much higher ambient temperatures than the small winter subadults. The most important investment shrews face during the adult period is reproduction, associated with territory expansion, territorial fights, and massive enlargement of the testes in the males and the production of several large litters in the females (Vlasák, 1996, 1998). The correlation of brain case height with precipitation might then be linked to the availability of high quality food during regrowth and reproduction since the abundance of the main prey of common shrews, the common earthworm (Churchfield, Rychlik, \& Taylor, 2012), is highly dependent on soil humidity. For both sexes reproduction appears to be a more or less terminal investment as most individuals die shortly after. Thus, regrowth with such a disproportional investment into mass instead of the brain might be driven by the demands of reproduction. This would mean that decrease and regrowth phases of Dehnel's phenomenon have evolved under different evolutionary pressures, which are caused and modulated by independent factors. Decrease intensity would then mainly be determined by the physiological limits of shrews, and the regrowth by reproduction. Across all reviewed populations, mean body mass decreased by $21.2 \pm 6.2 \%$ and regrew by $81.9 \pm 18.2 \%$. Similar to braincase height, the extent of body mass changes varied between populations in the analysis of literature data. We found a positive correlation between body mass decrease with longitude, and with the interaction of latitude X longitude, but not with altitude or in this case latitude alone (Fig. 1, Table 1). This matches results from a previous study where no correlation between winter body mass decline and latitude was found in S. araneus either (Ochocińska \& Taylor, 2003). Again, matching results of skull measures, body mass regrowth were not correlated with any geographical variable.

When comparing the three size extremes, there was no geographical pattern in juvenile or adult body mass. However, there was a significant negative correlation of body mass of winter subadults with latitude, longitude and their interaction, i.e. winter subadults had lower body mass towards Northeastern populations $(P$ (long.) $<0.05 ; P$ (lat. $)<0.001 ; P$ (long.:lat. $)<0.01)$. We found significant correlations between body mass decrease and most climate variables. In contrast, regrowth intensity was only negatively correlated with mean temperature during the driest quarter (the year quarter when precipitation is lowest) and, similar as in braincase height, positively correlated with precipitation seasonality (expressed as coefficient of variation, the more variation the more concentrated the precipitation on a period of the year; Table 2). Again these patterns support the hypothesis that different evolutionary drivers are responsible for the decrease - shrinking as an adaptation to save energy during cold periods with low resource availability, and the increase - growing a large body size well adapted for territory defense and to maximize reproductive output especially in females.

While the changes in body mass we describe are dramatic, seasonal fluctuations in body mass are common in mammals. For example, North American beavers (Castor canadensis ) lose 9-12\% of their body mass during autumn and winter, mainly because of the metabolic use of their fat stores (Smith \& Jenkins, 1997). During hibernation, marmots can lose $32 \%$ of their body mass (Lenihan \& Vuren, 1996), and hedgehogs 15-28\% (Haigh, O'Riordan, \& Butler, 2012). These fluctuations are mainly caused by changes in fat tissues. However, none of these species exhibit the changes in skull and brain size, which are characteristic of Dehnel's 
Phenomenon, as well as the changes in spine length (Saure \& Hyvärinen, 1965; Hyvarinen, 1969). Thus, changes in body mass are not exclusive of Dehnel's Phenomenon and should only be used to describe Dehnel's Phenomenon in combination with other variables, as the combination all these morphological changes - body mass, brain mass, skull size and spine length - are inherent parts of the unique Dehnel's phenomenon (see also general remarks below).

\section{Differences in seasonal skull dimensions and body mass between four populations of the com- mon shrew}

In our own previous work we used tooth row length measured from X-ray images as a factor to correct for individual size variation as it remained constant throughout the shrews' lifespan once summer juveniles were fully grown at our study site in Southern Germany (Lázaro et al. , 2017). Here, to use a calliper measurement in collection specimens (in some collections X-rays were not possible) we measured mandible length as a proxy to that correction factor. However, when looking at three additional populations (Žofín, Gugny and Białowieża) we found that mandible length varied between seasons (d.f. $=186$, adj. $R^{2}=0.19$, $F=5.3, P$ (seas.) $<0.05, P$ (loc.) $<0.001, P$ (seas.:loc.) $>0.1$ ). Results for size-corrected and absolute values did not significantly differ in Radolfzell. Consequently, we compared absolute values between the four populations. First we tested for the effect of sex, but found no significant effect of sex and its interactions on braincase height for all locations in the model comparisons $(\mathrm{AIC}(\mathrm{M} 1)=-79.2, \mathrm{AIC}(\mathrm{M} 2)=-67.8$; $\mathrm{ANOVA}$, $P>0.5$ ). Thus, we excluded sex from further comparisons of skull dimensions. This is interesting, as even though differences in behavior and energetic pressure should exist particularly during reproduction in the adults, and some sexual dimorphism was found in mandible morphology of $S$. araneus (Nováková \& Vohralík, 2017).

In the final model M2 $\left(\right.$ d.f.$=200$, adj. $R^{2}=0.78, F($ season $)=155.7, F$ (location) $=146.6, F$ (interaction seasons $\mathrm{X}$ location $)=1.3)$, we found a difference between seasons and locations at the factor level $(P<$ 0.001 both), but not their interaction $(P>0.1)$. The Tukey test revealed a decrease in braincase height from summer juveniles to winter subadults $(P<0.001)$ and an increase from winter subadults to adults $(P$ $<0.001$ ) at each location (Fig. 2, Table 3). Braincase height values for all seasons combined were highest in Gugny, followed by Radolfzell, Žofín and Białowieża $(P<0.05$ in all pair-wise comparisons, Table 3). Thus, shrews from the four populations differed in size, but the magnitude of Dehnel's Phenomenon did not. Our analyses of data from the literature confirmed a more pronounced decline in braincase height towards Northeastern populations at a large geographical scale. However, our review also revealed large levels of variation in winter size decline between populations within small areas (e.g. northern Germany (Schubarth, 1958)) and similar decline values in widely separated populations (e.g. southern Germany and central Finland (Skaren, 1964; Lázaro et al. , 2018a)). Our four focal populations did not follow the predicted pattern but they are all situated in central Europe and habitat differences might not be strong enough to cause the variation observed at a larger scale. Interesting is that size, as measured by braincase height did not follow the expected pattern either. Sorex araneus is smaller with increasing latitude in direct contradiction to Bergmann's rule. However, the two neighboring Polish populations differed more in size than Gugny (Northeastern Poland) and Radolfzell (Southern Germany), which were almost identical.

As previous studies had also found (Dehnel, 1949; Lázaro et al. , 2017, 2018a), braincase height changed most strongly than other skull metrics in all populations. Thus, we focus on results for braincase height here. To summarize, we only found a slight winter decrease in skull length and a spring increase in braincase width, only in Radolfzell. More details of the results for skull length and braincase width can be found in the Supporting Information (see Table S2).

Again similar to the results on braincase height, we found few differences in body mass between the more closely investigated populations (Radolfzell, Gugny and Žofín). Again we found no significant effect of sex on body mass variation between seasons $(\mathrm{AIC}(\mathrm{M} 1)=290.3$, AIC $(\mathrm{M} 2)=293.6$; ANOVA, $P>0.1)$ and pooled data of males and females in all analyses. Body mass differed significantly between seasons and locations at both factor and interaction levels $\left(\mathrm{M} 2\right.$, d.f.$=116$, adj. $R^{2}=0.88, F$ (seas.) $=424.2, F$ (loc.) $=13.8, F$ $($ seas.:loc. $)=2.8, P$ (seas.) $<0.001, P($ loc. $)>0.001, P$ (seas.:loc. $)>0.05)$. All three populations decreased 
from summer juvenile to winter subadult followed by a pronounced regrowth to adult (Table 3, Fig. 3, Tukey test, $P<0.001$ for all populations). Body mass was similar in juveniles and adults in all populations, but winter subadults from Žofín were lighter $(P<0.001)$. Žofín is the only high-altitude population in our dataset. Mountain populations suffer harsher winter conditions and we expected Dehnel's Phenomenon to be stronger in shrews at higher altitudes. The stronger body mass decline we found in Žofín supports Dehnel's Phenomenon as a seasonal adaptation. However, we do not see a matching difference in braincase height decline. This might mean that changes in body mass are more sensitive to local environmental differences and/or current conditions. For example, there is the little evidence for winter body mass decline in Norway (Frafjord, 2008), but a 27\% decline found at similar latitudes in Finland (Hyvärinen \& Heikura, 1971). Alternatively, given that data from the various sites were collected during completely different years, seasonal changes in body mass may have resulted from other causes independent from Dehnel's Phenomenon, for example, winter malnutrition or non-adaptive changes.

\section{Geographic differences in seasonal brain mass changes}

Literature on seasonal changes in mammalian brain size is scarce (see Supporting Information), but average brain mass of $S$. araneusdecreased by $20.9 \pm 5.6 \%$ from summer juveniles to winter subadults and regrew by $10.0 \pm 4.2 \%$ to adult size. This is the most remarkable aspect of Dehnel's phenomenon. The size of the mammalian brain, once fully grown, is usually more or less fixed and changes of this magnitude are unparalleled. Only the song brain of some birds reversibly changes by similar magnitudes (Nottebohm, 1981; Tramontin et al. , 1998). Experimentally induced changes in brain size, by starving or other environmental manipulations, result in changes of less than 5\% (Bedi \& Bhide, 1988). In humans, brain size increases during ontogeny, reaching a peak at the age of 20; then, after 45-50 years of age it undergoes a progressive, unidirectional decline of $11 \%$ over the next 40 years, as a result of ageing (Dekaban \& Sadowsky, 1978).

When we analyzed the compiled shrew literature data with regards to geographic variation in the intensity of seasonal size change we found only little variation between populations. However, in contrast to braincase height, we found no correlation between any geographic variable and the intensity of both decrease and regrowth of brain mass (Tables 1 and 2). When we looked at our own data from Gugny and Radolfzell in more detail, we again found no significant effect of sex on the variation of corrected brain mass (AIC(M1) $=-509.6$, AIC $(\mathrm{M} 2)=-509.7$; ANOVA, $P>0.1)$ and excluded it from the models. We did find significant variation between seasons at the factor level in the final model M2, but not between locations and their interaction (d.f . $=50$, adj. $R^{2}=0.45, F$ (seas.) $=22.5, F$ (loc.) $=0.5, F$ (seas.:loc.) $=2.1, P$ (seas.) $<0.001, P$ (loc.) $>0.5, P$ (seas.:loc.) $>0.1$ ). However, there was no difference in absolute brain mass at any of the age stages that could be explained by geographical variables either $(P>0.1$ for all models). At both locations there was a significant but similar decrease from summer juvenile to winter subadult (Tukey test, $P<0.001)$. Surprisingly we found no significant regrowth from winter subadult to adult $(P>0.1)$. Thus, corrected brain mass was similar at every stage in both populations (Table 3, Fig. 4). This lack of spring regrowth in brain mass contradicts previous research, where a significant regrowth in brain mass from winter to summer was found in all studied populations of S. araneus (Bielak \& Pucek, 1960; Pucek, 1970; Yaskin, 1994; Lázaro et al. , 2018a). In fact, in our own previous study of the Radolfzell population we found a significant regrowth of brain mass, with a maximum during July-August (Lázaro et al. , 2018a). The adult brains used for the present analyses were collected earlier (May-July). Especially in Gugny, we collected most adults in May when body mass regrowth peaks and which is when the regrowth peak is commonly measured. Thus, the adults we included here probably had not completed brain regrowth yet. This emphasizes the importance of timing data collection correctly and defining the size stages for studies of Dehnel's Phenomenon carefully. An accurate estimation of the maxima and minimum of the cycle is critical for the quantification of the change. Probably most studies of Dehnel's Phenomenon do not report exact maxima and minima, and consequently all values on change intensity presented here are timed with spring body mass maxima and thus underestimates of the actual change in brain mass. This must be considered when studying Dehnel's Phenomenon intensity as well as the cycle phenology.

Striking in our combined results is the discrepancy between variables. Changes in braincase height did not 
reflect changes in brain mass, unlike in previous studies (Bielak \& Pucek, 1960; Lázaro et al. , 2018a). The geographical patterns we found in braincase height decrease, were not reflected by patterns in brain mass changes. This is probably due to the small sample size of brain mass data. Only few studies (10 publications about the common shrew, the most intensively studied species) have investigated the seasonal changes in brain mass.

\section{Comparing seasonal changes in brain organization in two populations}

As previously published for the Radolfzell population, the results from Gugny confirm different patterns of decrease and/or regrowth (or lack of change) in the volume of each brain region (Fig. 5). As each region contributed to the overall decrease/regrowth of brain volume to a different extent, we observed a seasonal change in the organization of the brain. However, the pattern of decrease and regrowth in most brain regions was similar in Radolfzell and Gugny. Olfactory bulbs of females but not males significantly decreased from summer juveniles to winter subadults at both locations $(P<0.05)$ reflected by a significant interaction of age and sex $(F=4.2, P<0.05)$, but we found no difference in seasonal olfactory bulb size between Radolfzell and Gugny at neither factor nor interaction level $(P>0.1)$. The only other brain region where we found a different pattern between the sexes was the cerebellum but only in Radolfzell (see also Lázaro et al. 2018b). The cerebellum did not vary seasonally at either location $(P>0.5)$. However, subadult winter females in Radolfzell had larger cerebelli than males, while in Gugny we did not find this sexual dimorphism. Changes for all other brain regions are discussed for males and females together. Volume of the neocortex significantly declined from summer juveniles to winter subadults at both locations $(P<0.001)$. We found that summer juveniles have a larger neocortex in Gugny $(P<0.01)$, but we found no difference in winter, meaning that there was a more pronounced decrease in Gugny. We did not find a difference in neocortex volumes between winter subadults and adults at either location. The rhinal and piriform cortices decreased their volume from summer to winter $(P<0.01)$ and did not regrow in adults, again with no difference between locations. Also, overall striatum volume decreased from summer juveniles to winter $(P<0.001)$, but did not increase in adults $(P>0.5)$. Again, there was no difference between locations. Within the striatum, this pattern was repeated in the caudoputamen $(P$ (juv-sub $)<0.001 ; P($ sub-ad $)>0.5)$ and amygdala $(P$ (juv-sub) $<0.05 ; P$ (sub-ad) $>0.1)$, while the nucleus accumbens did not significantly change size at all. The overall volume of the hippocampus decreased from summer to winter $(P<0.05)$ and did not regrow in adults. There was no difference between locations. Within the hippocampus, volume decrease was only found in CA2 $(P$ (juv-sub) <0.05). Both the thalamus and hypothalamus decreased and regrew significantly, with no difference between locations (thalamus: $P$ (juv-sub) $<0.001 ; P($ sub-ad $)<0.05)$; hypothalamus: $(P$ $($ juv-sub) $<0.001 ; P($ sub-ad $)<0.001)$.

In summary, although each brain region makes a different contribution to the seasonal changes in brain size, giving rise to a marked re-organization of the brain structure along individuals' life. The seasonal changes in each brain region in Gugny are remarkably similar to the variation observed in Radolfzell, with the exception of a slight difference in neocortex winter decrease - more emphasized in Gugny - and a quite different pattern in the cerebellum. However, the lack of overall brain mass increase in spring in Gugny may be due to early sampling and the results in Lázaro et al. (2018b) from Radolfzell might describe these patterns better.

Interestingly, the structural changes described in Russia (Yaskin, 1994) largely differ from both Radolfzell and Gugny. The only brain region with a similar pattern is the neocortex, which is the structure that shows the greatest winter decline in all three populations - 37\% decline in Russia and Gugny, $28 \%$ in Radolfzell - although this is followed by a $18 \%$ spring regrowth in Russia, which we did not observe in the other populations. The paleocortex of Russian shrews shrinks/regrows $28 / 12 \%$ in mass respectively, more pronounced than the intermediate values in the corresponding regions - rhinal and piriform cortices - in Gugny (21/6\%), and the less pronounced changes in Radolfzell (18/4\%). This is the only brain structure that matches our expectation of a geographic and/or environmental gradient, with the Polish population intermediate between Russia and Germany. Hippocampus changes are much greater in Russia (29/33\%) than in Gugny (10/5\%) and Radolfzell (10/8\%), while the olfactory bulbs, which did not change seasonally in Russia, showed strong changes both in Radolfzell (14/14\%) and Gugny (24/12\%). These inconsistencies 
refute the hypothesis of a simple linear geographic trend. Instead, the differences in brain structure between populations and seasons might reflect local adaptations to specific climatic or habitat features. Nevertheless, we must also point out differences in the used methods. We used volumetric estimations derived from tracing brain regions in fixed, sectioned, and stained sections, while Yaskin (1994) weighed dissected tissue.

\section{Dehnel's phenomenon in other species and general remarks}

Sorex araneus is a model species for studies of Dehnel's Phenomenon. However, it is not the only species showing Dehnel's Phenomenon and, in fact, not showing the most extreme changes. We found literature on seasonal variation in braincase and/or brain size in 16 mammalian species, including $S$. araneus (see the species list and data summary in Table S3, Supporting Information). Seven of these species belong to the genus Sorex and 10 of them are shrews (Soricidae). Sorex minutus exhibits the most profound seasonal changes: its braincase height decreases 19.1\% in winter and regrows 15.5\% in spring (Kubik, 1951); and brain mass decreases by $34.3 \%$ and regrows by $20.3 \%$ (Caboń, 1956).

Most species showing Dehnel's Phenomenon are soricids and small mustelids. They have in common that are small, short-lived predators with high metabolisms, which are unable to use torpor or hibernate and which mostly delay reproduction to the following spring. Thus, Dehnel's Phenomenon might be a convergent adaptation to winter under similar conditions in these two phylogenetically distant groups (Dechmannet al. , 2017). This is confirmed by observations of decline in braincase and brain size in captive mustelids. Brains of captive ferrets (Mustela putorius ) shrink by 11-19\% during 10 months after a postnatal growth peak (Apfelbach \& Kruska, 1979; Weiler, 1992). A similar decrease of 14-18\% in brain mass was observed in mink from fur farms (Mustela vison) (Kruska, 1977) here also followed by $17 \%$ regrowth in adults (Kruska, 1993). However, we excluded these studies from our species list because the changes were not clearly linked to seasonality, and there is a known overall decreasing effect of domestication on brain size (Kruska, 1993).

We found one additional taxon where seasonal size changes were observed: the morphology of arvicoline voles (Rodentia) also changes seasonally (Yaskin, 1984, 2011, 2013), even though they have a lower metabolic rate than soricids and mustelids, subsist on low quality food and are able to reduce their metabolism in winter. And in fact, we postulate that the change in average size of skull or brain found at the population level in these species does not necessarily reflect individual size changes. Selective mortality of large individuals during summer and autumn can lead to a smaller mean body size in populations of voles and weasels in winter (Szafrańska, Zub, \& Konarzewski, 2013; Zub et al. , 2014). In contrast to shrews, which reproduce only in summer, arvicoline voles breed year-round. Variation similar to Dehnel's Phenomenon could then be caused by seasonal size differences in cohorts, with smaller animals born in autumn and winter, as is the case in some rodents and non-soricine shrews (Schwarz et al. , 1964; Dapson, 1968; Brown, 1973; Markowski \& Ostbye, 1992). Confounding Dehnel's Phenomenon and a seasonal cohort effect in Blarina brevicaudaI wrongly led to reject the existence of the phenomenon (Dapson, 1968). A mean size decrease at population level can also be caused by emigration of large individuals or recruitment of small ones (Iverson \& Turner, 1974). A "decline" caused by any of these processes, might be followed by an increase in mean size, caused by the inverted process or simply by continued individual growth, which then cannot be considered a "regrowth". Size-corrected analyses of carefully aged individuals, such as in Dechmann et al. (2017), LaPoint et al. (2017) and Lázaro et al. (2018a) are necessary to account for individual size variation and describe relative changes in the size of the brain. The only species for which Dehnel's Phenomenon in the skull and thus brain has been followed at the individual level is $S$. araneus (Lázaro et al. , 2017). Mean braincase height of our Southern German population in Radolfzell decreased by $12 \%$ between July and February (Lázaro et al. , 2018a). In that same population, recaptured individuals decreased by $15-20 \%$ during the same period (Lázaro et al. , 2017),indicating that the estimations at the population level might be biased by the factors mentioned above. Thus, when studying Dehnel's Phenomenon we must carefully choose the approach and methods.

This also emphasizes that body mass should only be used in combination with other variables to describe Dehnel's Phenomenon. Individual loss in body mass from summer to winter is common and can have different causes (Zub et al. , 2014). Most often it is simply a consequence of lack of resources in winter. Many species 
store fat resulting in a weight peak in late summer, followed by a decline along autumn and winter as they use it up. In contrast to the anticipatory shrinking of the shrew, which also includes the skeleton and many major organs, this body mass decrease is therefore not adaptive but a consequence of ambient conditions, which would not occur if resources were still available. Common shrews in captivity reduce food intake during winter and both body mass and braincase height decrease even when provided with food $a d$ libitum (Churchfield, 1982; Lázaro et al. , 2019). The two kinds of body mass changes - as a consequence of current ambient conditions $v s$. adaptive - are then regulated by different physiological processes, triggered and modulated by different external zeitgebers, and are ultimately the result of different evolutionary drivers (Hyvärinen, 1984). They must be studied under separated theoretical frameworks so as not to be confounded. We suggest that individual changes in skull dimensions and brain mass are the most distinctive features of the morphological changes associated with Dehnel's Phenomenon. Until the size changes of other organs have been better described for various populations, we recommend using the extracted or scanned skull and brain in combination with body mass to verify and measure Dehnel's Phenomenon.

As important as choosing the right morphological trait to measure is the correct timing of measurements. Our brain size results from Gugny indicate that choosing the wrong timing may profoundly affect how Dehnel's Phenomenon is described in a given study. To date, the phenology of Dehnel's Phenomenon has not been investigated. To the best of our knowledge, based on our own data and the information collected from literature, the time of the year at which each stage of Dehnel's Phenomenon takes place, may vary between populations and perhaps even between years. In the common shrew the first size peak in the summer juveniles occurs between June and August; the minimum in winter subadults has been reported between December and March; and the second peak, in sexually mature adults, is reached between May and August. The timing at each site may differ. Also, the duration of both decrease and regrowth phases have a strong impact on individuals' biology, as it determines the rate of tissue shrinkage or regeneration. Viktorov (1967) suggested a possible geographic trend in Dehnel's Phenomenon phenology: the braincase regrowth phase tends to shorten from western (UK) to eastern (Russia) Europe, in contrast to the rate of regrowth which increases towards eastern populations. Studying the specific timing of each peak and minimum in each population might reveal correlations with current environmental factors and therefore provide more information on the triggers and evolutionary drivers of Dehnel's Phenomenon. Such added knowledge of the exact timing of the change of each tissue (bone, brain region or organ) in conjunction with studies of gene expression and the detailed mechanisms involved will be important to truly interpret the adaptive value of Dehnel's Phenomenon. For example, the fact that the brain is largest in young dispersing juveniles and then only partially regrows in reproductive adults, which instead invest in larger body mass suggests that different drivers lead to the shrinking and the regrowth but only a detailed and holistic quantification of the costs and functions of various tissues at each stage will allow us to answer this. Perhaps then, we can understand more general questions, such as why soricine shrews and small mustelids pursue the risky strategy of reproducing only so close to the end of their brief lifespan.

\section{REFERENCES}

Apfelbach, V.R. \& Kruska, D. (1979) Zur postnatalen Hirnentwicklung beim Frettchen Mustela putorius f. furo(Mustelidae; Mammalia). Zeitschrift für Säugetierkunde44, 127-131.

Bedi, K.S. \& Bhide, P.G. (1988) Effects of environmental diversity on brain morphology. Early Human Development 17 , 107-143.

Bergmann, C. (1848) Über die Verhältnisse der Wärmeökonomie der Thiere zu ihrer Grösse .

Bielak, T. \& Pucek, Z. (1960) Seasonal changes in the brain weight of the common shrew (Sorex araneus Linnaeus: 1758).Acta Theriologica $13,297-300$.

Brown, E.B. (1973) Changes in patterns of seasonal growth of Microtus pennsylvanicus. Ecology 54, 11031110.

Caboń, K. (1956) Untersuchungen über die saisonale Veränderlichkeit der Gehirnes bei der kleinen Spitsmaus 
(Sorex minutus minutus L.). Annales of the University of Marie Curie-Sklodowska, Section C 10 , 93-105.

Churchfield, S. (1982) The influence of temperature on the activity and food consumption of the common shrew. Acta Theriologica 27 , 295-304.

Churchfield, S. (1990) The Natural History of Shrews . Christopher Helm, Bromley.

Churchfield, S., Rychlik, L. \& Taylor, J.R.E. (2012) Food resources and foraging habits of the common shrew, Sorex araneus: does winter food shortage explain Dehnel's phenomenon? Oikos 121 , 1593-1602.

Crowcroft, P. \& Ingles, J.M. (1959) Seasonal changes in the brain-case of the common shrew (Sorex araneus L.). Nature 193 , 907-908.

Dapson, R.W. (1968) Growth patterns in a post-juvenile population of short-tailed shrews (Blarina brevicauda ).American Midland Naturalist 79 , 118-129.

Dechmann, D.K.N., LaPoint, S., Dullin, C., Hertel, M., Taylor, J.R.E., Zub, K. \& Wikelski, M. (2017) Profound seasonal shrinking and regrowth of the ossified braincase in phylogenetically distant mammals with similar life histories. Scientific Reports 7, 42443.

Dehnel, A. (1949) Studies on the genus Sorex L.Annales of the University of Marie Curie-Sklodowska, Section C4, 17-102.

Dekaban, A.S. \& Sadowsky, D. (1978) Changes in brain weights during the span of human life : relation of brain weights to body heights and body weights. Annals of Neurology 4 , 345-356.

Frafjord, K. (2008) Can environmental factors explain size variation in the common shrew (Sorex araneus )? Mammalian Biology - Zeitschrift fur Saugetierkunde 73 , 415-422.

Gebczyński, M. (1965) Seasonal and age changes in the metabolism and activity of Sorex araneus Linnaeus 1758. Acta Theriologica 10 , 303-331.

Haigh, A., O'Riordan, R.M. \& Butler, F. (2012) Nesting behaviour and seasonal body mass changes in a rural Irish population of the Western hedgehog (Erinaceus europaeus ).Acta Theriologica 57, 321-331.

Hijmans, R.J., Cameron, S.E., Parra, J.L., Jones, P.G. \& Jarvis, A. (2005) Very high resolution interpolated climate surfaces for global land areas. International Journal of Climatology 25 , 1965-1978.

Homolka, M. (1980) Biometrischer Vergleich zweier PopulationenSorex araneus . Acta Scientiarum Naturalium Academiae Scientiarum Bohemicae Brno 14 , 1-34.

Hyvärinen, H. (1969) On the seasonal changes in the skeleton of the common shrew (Sorex araneus L.) and their physiological background. Aquilo (Series Zoologica) 7 , 2-32.

Hyvärinen, H. (1984) Wintering strategy of voles and shrews in Findland. In Winter Ecology of Small Mammals pp. 139-148.

Hyvärinen, H. \& Heikura, K. (1971) Effects of age and seasonal rhythm on the growth patterns of some small mammals in Finland and in Kirkenes, Norway. Journal of Zoology 165 , 545-556.

Iverson, S.L. \& Turner, B.N. (1974) Winter weight dynamics in Microtus pennsylvanicus . Ecology 55 , 1030-1041.

Kruska, D. (1977) Über die postnatale Hirnentwicklung beim Farmnerz Mustela vison f. dom . (Mustelidae; Mammalia).Zeitschrift für Säugetierkunde 42 , 240-255.

Kruska, D. (1993) Evidence of decrease in brain size in ranch mink, Mustela vison f. dom ., during subadult postnatal ontogenesis. Brain, Behavior and Evolution 41, 303-315.

Kubik, J. (1951) Analysis of the Pulawy population ofSorex araneus araneus L. and Sorex minutus minutus L.Annales of the University of Marie Curie-Sklodowska, Section C11 , 335-372. 
LaPoint, S., Keicher, L., Wikelski, M., Zub, K. \& Dechmann, D.K.N. (2017) Growth overshoot and seasonal size changes in the skulls of two weasel species.Open Science 4, 160947.

Lázaro, J., Dechmann, D.K.N., LaPoint, S., Wikelski, M. \& Hertel, M. (2017) Profound reversible seasonal changes of individual skull size in a mammal. Current Biology 27, R1106-R1107.

Lázaro, J., Hertel, M., LaPoint, S., Wikelski, M., Stiehler, M. \& Dechmann, D.K.N. (2018a) Cognitive skills of common shrews (Sorex araneus) vary with seasonal changes in skull size and brain mass. Journal of Experimental Biology 221 .

Lázaro, J., Hertel, M., Muturi, M. \& Dechmann, D.K.N. (2019) Seasonal reversible size changes in the braincase and mass of common shrews are flexibly modified by environmental conditions. Scientific Reports 9.

Lázaro, J., Hertel, M., Sherwood, C.C., Muturi, · Marion \& Dechmann, D.K.N. (2018b) Profound seasonal changes in brain size and architecture in the common shrew.Brain Structure and Function 223 , 2823-2840.

Lenihan, C. \& Vuren, D. Van (1996) Growth and survival of juvenile yellow-bellied marmots (Marmota flaviventris ). Canadian Journal of Zoology 74, 297-302.

Markowski, J. \& Ostbye, E. (1992) Morphological variability of a root vole population in high mountain habitats, Hardangervidda, South Norway. Acta Theriologica 37 , 117-139.

McNab, B.K. (2010) Geographic and temporal correlations of mammalian size reconsidered: a resource rule. Oecologia164, 13-23.

Mezhzherin, V.A. (1964) Dehnel's phenomenon and its possible explanation. Acta Theriologica 8 , 95-114.

Nottebohm, F. (1981) A brain for all seasons: cyclical anatomical changes in song control nuclei of the canary brain.Science 214, 1368-1370.

Nováková, L. \& Vohralík, V. (2017) Age and sex skull variation in a model population of the common shrew (Sorex araneus ). Folia Zoologica 66 , 254-261.

Ochocińska, D. \& Taylor, J.R.E. (2003) Bergmann's rule in shrews: geographical variation of body size in PalearcticSorex species. Biological Journal of the Linnean Society78 , 365-381.

Ochocińska, D. \& Taylor, J.R.E. (2005) Living at the physiological limits: field and maximum metabolic rates of the common shrew (Sorex araneus). Physiological and biochemical zoology : PBZ 78, 808-818.

Pankakoski, E. (1989) Variation in the tooth wear of the shrewsSorex araneus and S. minutus . Annales Zoologici Fennici 26 , 445-457.

Piersma, T. \& Drent, J. (2003) Phenotypic flexibility and the evolution of organismal design. Trends in Ecology and Evolution 18, 228-233.

Pucek, Z. (1965) Seasonal and age changes in the weight of internal organs of shrews. Acta Theriologica 10 , 369-438.

Pucek, Z. (1970) Seasonal and age change in shrews as an adaptive process. Symp. Zool. Soc. Lond. 26 , 189-207.

R Core Team (2015) R: A language and environment for statistical computing. R Foundation for Statistical Computing, Vienna. Http://www.r-project.org/.

Saure, L. \& Hyvärinen, H. (1965) Seasonal changes in the histological structure of the spinal column of Sorex araneus(L.). Nature $208,705-706$.

Schaeffer, P.J., O’Mara, M.T., Breiholz, J., Keicher, L., Lázaro, J., Muturi, M. \& Dechmann, D.K.N. (2020) Metabolic rate in common shrews is unaffected by temperature, leading to lower energetic costs through seasonal size reduction. Royal Society Open Science 7, 191989. 
Schubarth, H. (1958) Zur Variabilität von Sorex araneus araneus L. Acta Theriologica 2 , 175-202.

Schwarz, S.S., Pokrovski, A. V, Istchenko, V.G., Olenjev, V.G., Ovtschinnikova, N.A. \& Pjastolova, O.A. (1964) Biological peculiarities of seasonal generations of rodents, with special reference to the problem of senescence in mammals. Acta Theriologica $8,11-43$.

Skaren, U. (1964) Variations in two shrews, Sorex unguiculatus Dobson and S. a. araneus L. Annales Zoologici Fennici $1,94-124$.

Smith, D.W. \& Jenkins, S.H. (1997) Seasonal change in body mass and size of tail of northern beavers. Journal of Mammalogy 78, 869-876.

Spitzenberger, F. (2001) Die Säugetierfauna Österreichs . In Wasserwirtschaft p. Austria Medien-Service.

Stephan, H. (1960) Methodische Studien über den quantitativen Vergleich architektonischer Struktureinheiten des Gehirns.Zeitschrift Fur Wissenschartliche Zoologie 164, 143-172.

Szafrańska, P. a., Zub, K. \& Konarzewski, M. (2013) Seasonal variation of resting metabolic rate and body mass in free-living weasels Mustela nivalis . Physiological and Biochemical Zoology 86 , 791-798.

Taylor, J.R.E. (1998) Evolution of energetic strategies in shrews. In Evolution of Shrews (eds J.M. Wojcik \& M. Woslan), pp. 309-346. Mammal Research Institute, Polish Academy of Sciences, Bialowieza.

Taylor, J.R.E., Rychlik, L. \& Churchfield, S. (2013) Winter reduction in body mass in a very small, nonhibernating mammal: consequences for heat loss and metabolic rates. Physiological and biochemical zoology : $P B Z \mathbf{8 6}, 9-18$.

Tramontin, A.D., Smith, G.T., Breuner, C.W. \& Brenowitz, E.A. (1998) Seasonal plasticity and sexual dimorphism in the avian song control system: Stereological measurement of neuron density and number. Journal of Comparative Neurology396, 186-192.

Viktorov, L. V. (1967) Geografičeskije osobennosti 'javlenija Dehnelja”' u zemlerojek Evropy'. Bull. Mosc. Obschch. Ispyt. Prir. 72, 159-160.

Vlasák, P. (1996) Reproduction of the Common Shrew (Sorex araneus ) in the Czech and the Slovak Republic. Acta-Universitatis Carolinae Biologica $40,351-364$.

Vlasák, P. (1998) Size of litters of the common shrew (Sorex araneus) in the Czech and the Slovak Republics.Acta-Universitatis Carolinae Biologica 42, 43-50.

Weiler, E. (1992) Seasonal changes in adult mammalian brain weight. Naturwissenschaften 79 , 474-476.

Yaskin, V. a (1984) Seasonal changes in brain morphology in small mammals. Special Publication Carnegie Museum of Natural History 10, 183-191.

Yaskin, V.A. (1994) Variation in brain morphology of the common shrew. In Advances in the Biology of Shrews (eds J.F. Merrit, G.L. Kirkland \& R.K. Rose), pp. 155-161. Carnegie Museum of Natural History, special publication, Pittsburgh.

Yaskin, V.A. (2011) Seasonal changes in hippocampus size and spatial behaviour in mammals and birds. Biology Bulletin Reviews1, 279-288.

Yaskin, V.A. (2013) Seasonal modulation of sex-related differences in hippocampus size and spatial behavior in bank voles, Clethrionomys glareolus (Rodentia, Cricetidae). Russian Journal of Ecology 44, 221-226.

Yom-Tov, Y. \& Yom-Tov, J. (2005) Global warming, Bergmann's rule and body size in the masked shrew Sorex cinereusKerr in Alaska. Journal of Animal Ecology 74, 803-808.

Zeveloff, S.I. \& Boyce, M.S. (1988) Body size patterns in North American mammalian faunas. In Evolution of Life Histories of Mammals (ed M.S. Boyce), pp. 123-146. Yale University Press, Yale. 
Zub, K., Borowski, Z., Szafrańska, P. a., Wieczorek, M. \& Konarzewski, M. (2014) Lower body mass and higher metabolic rate enhance winter survival in root voles, Microtus oeconomus. Biological Journal of the Linnean Society , 297-309.

\section{DATA ACESSIBILITY}

-Morphological and climate data collected from literature: Table S1 (Supplementary Information).

-Primary data on skull and brain morphology uploaded as online supplementary information

\section{AUTHOR CONTRIBUTIONS}

J.L., L.K., M.H. and D.N.K.D. conceived the ideas; J.L, L.K., J.R.E.T, M.M. and K.Z. collected the data; J.L. and L.K. analysed the data; J.L. and D.N.K.D. led the writing; all authors contributed to the final draft of the manuscript.

\section{ACKNOWLEDGEMENTS}

We are grateful to Vladimír Vohralík and Miloš Anděra for their help with the zoological collection at the Charles University in Prague. The fieldwork conducted in Gugny was based at the field station of the Faculty of Biology, University of Bialystok. This study was supported financially by the Max Planck-Poland Biodiversity Initiative. LN was funded by Grant Agency of Charles University, GAUK no. 40216 and by Charles University, grant SVV no. 260 434/2019.

\section{Figure legends}

Figure 1. Intensity (\%) of decrease in braincase height and body mass in different populations of common shrew across Europe.

Figure 2. Seasonal variation in braincase height in the four populations analyzed in detail.

Figure 3. Seasonal variation in body mass in the four populations analyzed in detail.

Figure 4. Seasonal variation in corrected brain mass in Gugny and Radolfzell with fitted Generalized Additive Model, using jday as smooth term $(\mathrm{s}), \mathrm{k}=5$. Solid line and shaded area represent fitted values and standard error of the model, respectively (e.d.f. $=3.67, \mathrm{~F}(\mathrm{~s})=14, \mathrm{P}(\mathrm{s})<0.001$, deviance explained $=38.4 \%$ ). This fitted model helps to illustrate how adult Gugny brains were collected before the second size peak.

Figure 5. Variation between seasons and sexes in corrected volume of brain regions in Radolfzell (blue) and Gugny (red). As in Fig.4, the too early collection of adult brains in Gugny is evident.

Table 1. Results from linear models to test correlation between intensity of Dehnel's Phenomenon and geographical variables

\begin{tabular}{lllll}
\hline Brain case height decrease & Brain case height decrease & Brain case height decrease & Brain case height decrease & Brain \\
\hline & $\mathrm{F}$ & $\mathrm{DF}$ & Adj-R2 & $\mathrm{P}$ \\
latitude & 5.6 & 17 & 0.20 & $<0.0$ \\
longitude & 5.3 & 17 & 0.19 & $<0.0$ \\
lat. X long. & 17 & 0.24 & $>0.5$ \\
altitude & 15.6 & 0.01 & Brain \\
Brain case height regrowth & Brain case height regrowth & Brain case height regrowth & Brain case height regrowth & $>0.1$ \\
latitude & 0.1 & 14 & 0.03 & $>0.5$ \\
longitude & 0.4 & 14 & 0.04 & $>0.1$ \\
lat. X long. & 0.5 & 14 & 0.03 & $>0.1$ \\
altitude & 2.2 & Brain mass decrease & 0.09 & Brain mass decrease \\
Brain mass decrease & Brain mass decrease & 8 & 0.12 & $>0.5$ \\
latitude & 0.1 & & &
\end{tabular}




\begin{tabular}{llllr}
\hline Brain case height decrease & Brain case height decrease & Brain case height decrease & Brain case height decrease & Brain \\
\hline longitude & 0.2 & 8 & 0.10 & $>0.5$ \\
lat. X long. & 0.2 & 8 & 0.10 & $>0.5$ \\
altitude & 0.5 & 8 & 0.06 & $>0.1$ \\
Brain mass regrowth & Brain mass regrowth & Brain mass regrowth & Brain mass regrowth & Brain \\
latitude & 2.8 & 7 & 0.18 & $>0.1$ \\
longitude & 0.7 & 7 & 0.03 & $>0.1$ \\
lat. X long. & 0.7 & 7 & 0.04 & $>0.1$ \\
altitude & 4.5 & Body mass decrease & 0.30 & $>0.0$ \\
Body mass decrease & Body mass decrease & 24 & Body mass decrease & Body \\
latitude & 2.5 & 24 & 0.06 & $>0.1$ \\
longitude & 10.8 & 24 & 0.27 & $<0.0$ \\
lat. X long. & 10.2 & 24 & 0.03 & $<0.0$ \\
altitude & 0.7 & Body mass regrowth & Body mass regrowth & $>0.1$ \\
Body mass regrowth & Body mass regrowth & 18 & 0.03 & Body \\
latitude & 0.4 & 18 & 0.08 & $>0.5$ \\
longitude & 2.6 & 18 & 0.06 & $>0.1$ \\
lat. X long. & 2.3 & 18 & 0.01 & $>0.1$ \\
altitude & 0.9 & & $>0.1$ \\
\hline
\end{tabular}

Table 2. Results from linear models testing correlation between intensity of Dehnel's Phenomenon and climate variables.

\begin{tabular}{llll}
\hline Brain case height decrease & Brain case height decrease & Brain case height decrease & Brain case height decre \\
\hline & $\mathrm{F}$ & $\mathrm{DF}$ & Adj-R2 \\
annual mean temperature & 0.2 & 17 & 0.05 \\
mean diurnal temperature range & 0.3 & 17 & 0.04 \\
isothermality & 5.4 & 17 & 0.20 \\
temperature seasonality & 9.0 & 17 & 0.31 \\
max. temperature of warmest month & 0.9 & 17 & 0.01 \\
min. temperature of coldest month & 3.1 & 17 & 0.11 \\
temperature annual range & 9.8 & 17 & 0.33 \\
mean temperature of wettest quarter & 1.5 & 17 & 0.03 \\
mean temperature of driest quarter & 24.8 & 17 & 0.57 \\
mean temperature of warmest quarter & 1.1 & 17 & 0.00 \\
mean temperature of coldest quarter & 2.6 & 17 & 0.08 \\
annual precipitation & 0.0 & 17 & 0.03 \\
precipitation of wettest month & 0.0 & 17 & 0.06 \\
precipitation of driest month & 1.5 & 17 & 0.03 \\
precipitation seasonality & 7.6 & 17 & 0.27 \\
precipitation of wettest quarter & 2.3 & 17 & 0.06 \\
precipitation of driest quarter & 2.1 & 17 & 0.06 \\
precipitation of warmest quarter & 0.1 & 17 & 0.05 \\
precipitation of coldest quarter & 2.9 & 17 & 0.10 \\
Brain case height regrowth & Brain case height regrowth & Brain case height regrowth & Brain case height regro \\
annual mean temperature & 2.9 & 14 & 0.06 \\
mean diurnal temperature range & 0.2 & 14 & 0.06 \\
isothermality & 0.2 & 14 & 0.05 \\
temperature seasonality & 1.1 & 14 & 0.01 \\
max. temperature of warmest month & 1.2 & 14 & 0.01
\end{tabular}




\begin{tabular}{|c|c|c|c|}
\hline Brain case height decrease & Brain case height decrease & Brain case height decrease & Brain case height decre \\
\hline min. temperature of coldest month & 0.0 & 14 & 0.07 \\
\hline temperature annual range & 1.4 & 14 & 0.03 \\
\hline mean temperature of wettest quarter & 1.2 & 14 & 0.01 \\
\hline mean temperature of driest quarter & 1.8 & 14 & 0.05 \\
\hline mean temperature of warmest quarter & 1.0 & 14 & 0.00 \\
\hline mean temperature of coldest quarter & 0.0 & 14 & 0.07 \\
\hline annual precipitation & 1.6 & 14 & 0.04 \\
\hline precipitation of wettest month & 3.4 & 14 & 0.14 \\
\hline precipitation of driest month & 1.4 & 14 & 0.03 \\
\hline precipitation seasonality & 0.1 & 14 & 0.06 \\
\hline precipitation of wettest quarter & 3.5 & 14 & 0.14 \\
\hline precipitation of driest quarter & 0.9 & 14 & 0.01 \\
\hline precipitation of warmest quarter & 5.0 & 14 & 0.21 \\
\hline precipitation of coldest quarter & 0.0 & 14 & 0.07 \\
\hline Brain mass decrease & Brain mass decrease & Brain mass decrease & Brain mass decrease \\
\hline annual mean temperature & 0.1 & 8 & 0.11 \\
\hline mean diurnal temperature range & 0.2 & 8 & 0.09 \\
\hline isothermality & 0.0 & 8 & 0.12 \\
\hline temperature seasonality & 0.1 & 8 & 0.12 \\
\hline max. temperature of warmest month & 0.5 & 8 & 0.06 \\
\hline min. temperature of coldest month & 0.1 & 8 & 0.12 \\
\hline temperature annual range & 0.1 & 8 & 0.11 \\
\hline mean temperature of wettest quarter & 0.1 & 8 & 0.11 \\
\hline mean temperature of driest quarter & 0.1 & 8 & 0.12 \\
\hline mean temperature of warmest quarter & 0.1 & 8 & 0.11 \\
\hline mean temperature of coldest quarter & 0.1 & 8 & 0.12 \\
\hline annual precipitation & 0.1 & 8 & 0.12 \\
\hline precipitation of wettest month & 0.6 & 8 & 0.05 \\
\hline precipitation of driest month & 0.1 & 8 & 0.11 \\
\hline precipitation seasonality & 0.0 & 8 & 0.12 \\
\hline precipitation of wettest quarter & 0.2 & 8 & 0.10 \\
\hline precipitation of driest quarter & 0.0 & 8 & 0.12 \\
\hline precipitation of warmest quarter & 0.2 & 8 & 0.10 \\
\hline precipitation of coldest quarter & 0.1 & 8 & 0.11 \\
\hline Brain mass regrowth & Brain mass regrowth & Brain mass regrowth & Brain mass regrowth \\
\hline annual mean temperature & 1.1 & 7 & 0.02 \\
\hline mean diurnal temperature range & 0.1 & 7 & 0.13 \\
\hline isothermality & 1.7 & 7 & 0.08 \\
\hline temperature seasonality & 0.9 & 7 & 0.01 \\
\hline max. temperature of warmest month & 1.8 & 7 & 0.09 \\
\hline min. temperature of coldest month & 1.0 & 7 & 0.00 \\
\hline temperature annual range & 0.8 & 7 & 0.03 \\
\hline mean temperature of wettest quarter & 5.2 & 7 & 0.34 \\
\hline mean temperature of driest quarter & 1.2 & 7 & 0.03 \\
\hline mean temperature of warmest quarter & 5.2 & 7 & 0.34 \\
\hline mean temperature of coldest quarter & 1.0 & 7 & 0.00 \\
\hline annual precipitation & 3.0 & 7 & 0.20 \\
\hline precipitation of wettest month & 4.4 & 7 & 0.30 \\
\hline precipitation of driest month & 2.1 & 7 & 0.12 \\
\hline precipitation seasonality & 0.3 & 7 & 0.10 \\
\hline
\end{tabular}




\begin{tabular}{|c|c|c|c|}
\hline Brain case height decrease & Brain case height decrease & Brain case height decrease & Brain case height decre \\
\hline precipitation of wettest quarter & 4.1 & 7 & 0.28 \\
\hline precipitation of driest quarter & 2.3 & 7 & 0.14 \\
\hline precipitation of warmest quarter & 4.1 & 7 & 0.28 \\
\hline precipitation of coldest quarter & 2.0 & 7 & 0.11 \\
\hline Body mass decrease & Body mass decrease & Body mass decrease & Body mass decrease \\
\hline annual mean temperature & 6.6 & 24 & 0.18 \\
\hline mean diurnal temperature range & 3.6 & 24 & 0.10 \\
\hline isothermality & 8.4 & 24 & 0.23 \\
\hline temperature seasonality & 13.5 & 24 & 0.33 \\
\hline max. temperature of warmest month & 0.8 & 24 & 0.01 \\
\hline min. temperature of coldest month & 10.5 & 24 & 0.28 \\
\hline temperature annual range & 13.7 & 24 & 0.34 \\
\hline mean temperature of wettest quarter & 6.1 & 24 & 0.17 \\
\hline mean temperature of driest quarter & 16.3 & 24 & 0.38 \\
\hline mean temperature of warmest quarter & 0.0 & 24 & 0.04 \\
\hline mean temperature of coldest quarter & 10.5 & 24 & 0.28 \\
\hline annual precipitation & 4.0 & 24 & 0.11 \\
\hline precipitation of wettest month & 0.1 & 24 & 0.04 \\
\hline precipitation of driest month & 6.4 & 24 & 0.18 \\
\hline precipitation seasonality & 9.0 & 24 & 0.24 \\
\hline precipitation of wettest quarter & 0.4 & 24 & 0.03 \\
\hline precipitation of driest quarter & 7.9 & 24 & 0.22 \\
\hline precipitation of warmest quarter & 0.8 & 24 & 0.01 \\
\hline precipitation of coldest quarter & 10.4 & 24 & 0.27 \\
\hline Body mass regrowth & Body mass regrowth & Body mass regrowth & Body mass regrowth \\
\hline annual mean temperature & 1.8 & 18 & 0.04 \\
\hline mean diurnal temperature range & 0.7 & 18 & 0.02 \\
\hline isothermality & 3.1 & 18 & 0.10 \\
\hline temperature seasonality & 2.9 & 18 & 0.09 \\
\hline max. temperature of warmest month & 0.2 & 18 & 0.04 \\
\hline min. temperature of coldest month & 2.2 & 18 & 0.06 \\
\hline temperature annual range & 2.4 & 18 & 0.07 \\
\hline mean temperature of wettest quarter & 2.1 & 18 & 0.05 \\
\hline mean temperature of driest quarter & 5.3 & 18 & 0.18 \\
\hline mean temperature of warmest quarter & 0.0 & 18 & 0.06 \\
\hline mean temperature of coldest quarter & 2.4 & 18 & 0.07 \\
\hline annual precipitation & 0.1 & 18 & 0.05 \\
\hline precipitation of wettest month & 1.0 & 18 & 0.00 \\
\hline precipitation of driest month & 0.5 & 18 & 0.02 \\
\hline precipitation seasonality & 4.7 & 18 & 0.16 \\
\hline precipitation of wettest quarter & 0.5 & 18 & 0.02 \\
\hline precipitation of driest quarter & 1.2 & 18 & 0.01 \\
\hline precipitation of warmest quarter & 2.9 & 18 & 0.09 \\
\hline precipitation of coldest quarter & 1.7 & 18 & 0.04 \\
\hline
\end{tabular}

Table 3. Summary of morphological changes between the stages of Dehnel's Phenomenon in the four studied populations. $\mathrm{BCH}=$ braincase height. 


\begin{tabular}{|c|c|c|c|c|}
\hline & summer juvenile & summer juvenile & summer juvenile & winter subadult \\
\hline BCH (mm) & $\mathrm{n}$ & mean $\pm \mathrm{SE}$ & period & $\mathrm{n}$ \\
\hline Radolfzell & 20 & $6.21 \pm 0.04$ & Jun-Jul & 10 \\
\hline Gugny & 8 & $6.46 \pm 0.07$ & Jun-Jul & 8 \\
\hline Žofín & 9 & $5.96 \pm 0.04$ & Jul & 27 \\
\hline Białowieża & 23 & $5.62 \pm 0.05$ & Jun & 4 \\
\hline Corr. brain mass $(\mathrm{g} / \mathrm{mm})$ & Corr. brain mass $(\mathrm{g} / \mathrm{mm})$ & Corr. brain mass $(\mathrm{g} / \mathrm{mm})$ & & \\
\hline Radolfzell & 12 & $0.035 \pm 0.001$ & Jun-Jul & 4 \\
\hline Gugny & 6 & $0.038 \pm 0.001$ & Jun-Jul & 8 \\
\hline \multicolumn{5}{|l|}{ Body mass (g) } \\
\hline Radolfzell & 8 & $8.37 \pm 0.14$ & Jul & 7 \\
\hline Gugny & 10 & $7.79 \pm 0.10$ & Jun-Jul & 8 \\
\hline Žofín & 10 & $8.15 \pm 0.21$ & Aug & 26 \\
\hline
\end{tabular}

Braincase height decrease (\%)

$$
\begin{array}{llll}
10 & 12 & 14 & 16
\end{array}
$$

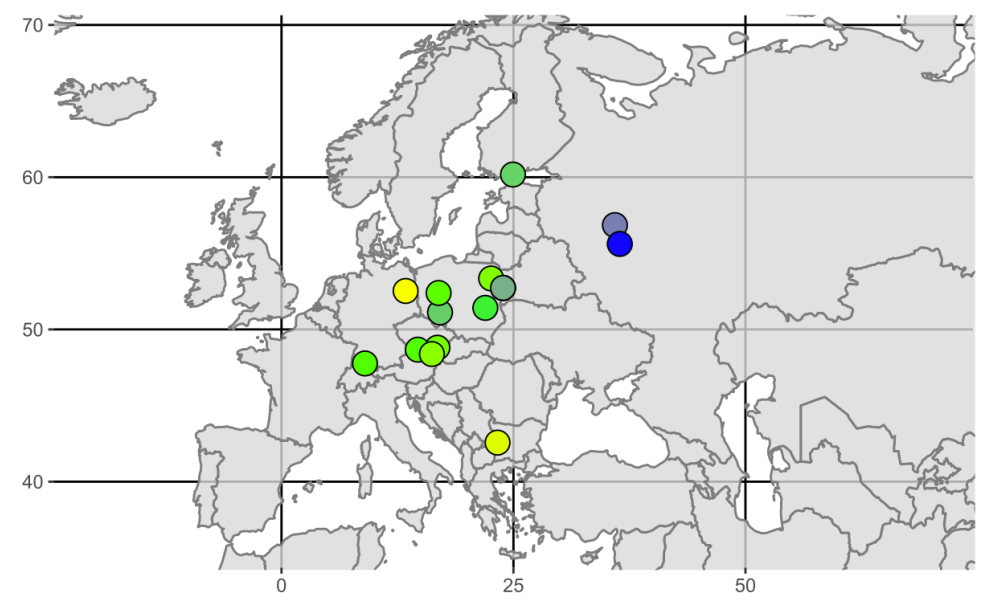

Body mass decrease (\%) 1015202530

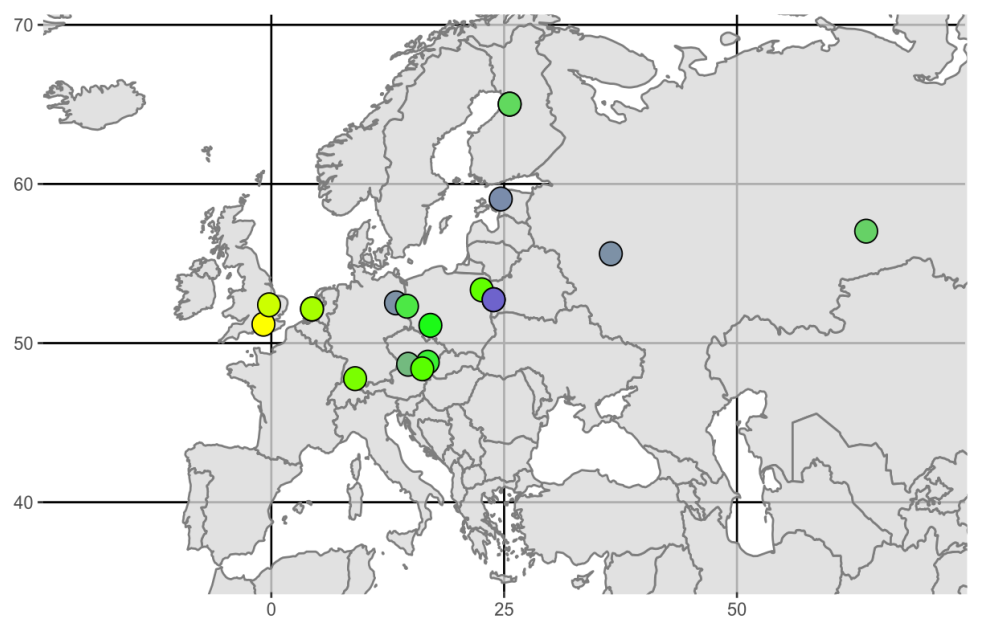



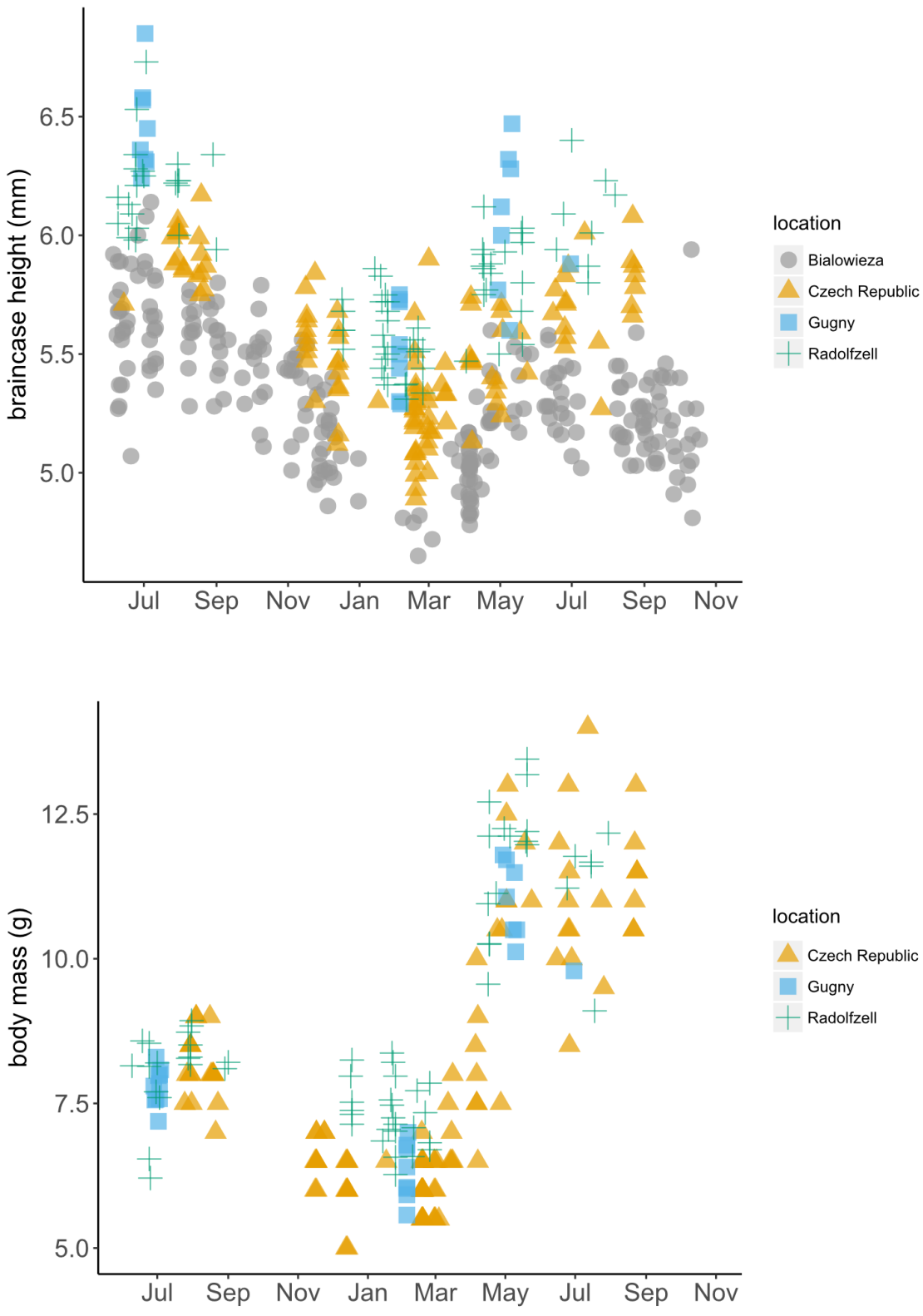

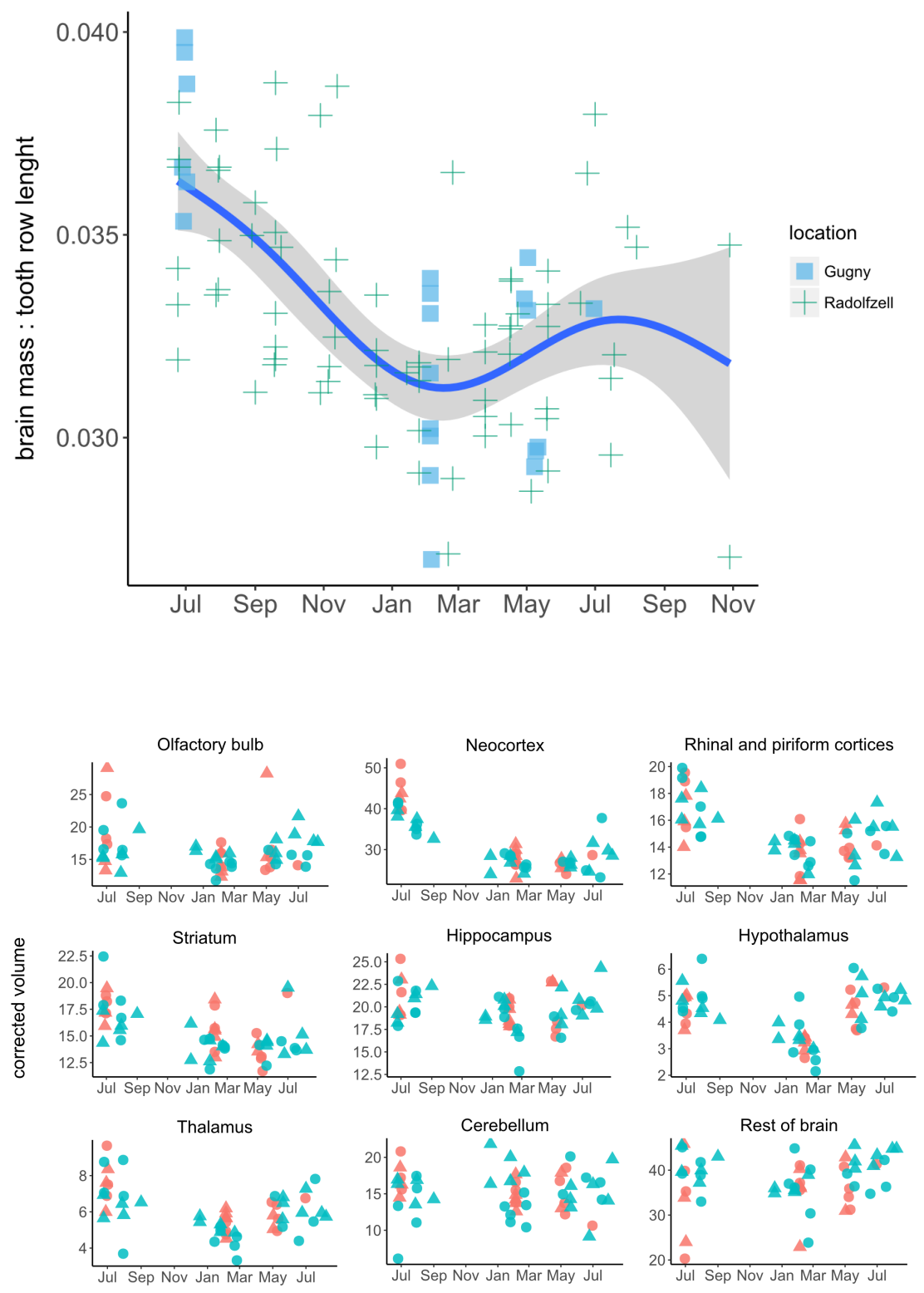